\title{
EFEITO DA VARIAÇÃO DO PPC DO MINÉRIO NO PROCESSO DE PELOTIZAÇÃO DA VALE*
}

\author{
Ronie Magno Pinheiro de Souza ${ }^{1}$ \\ Luis Henrique Torres Dantas ${ }^{1}$ \\ Marcos Vinícius de Barros ${ }^{1}$ \\ Camila Luzia Lira Duarte ${ }^{1}$ \\ Ana Luiza Baeta Costa ${ }^{1}$ \\ João Sérgio Agostinho Bonzi² \\ Tiago Gonçalves da Silva ${ }^{2}$ \\ Fernando Luiz Câmara Campos Júnior ${ }^{3}$ \\ Benito Barbabela e Silva ${ }^{3}$ \\ Frederico Correa Mayerhofer ${ }^{4}$
}

Resumo

A partir do segundo semestre de 2013, iniciou-se um período de maior dispêndio energético para o controle da resistência à compressão da pelota AFXX. A este problema somou-se o desafio de atingir elevados patamares de produção e chegar à produção nominal da usina. Desta forma, foi necessário fazer a partir de um complexo diagnóstico de todas as etapas do processo para encontrar a causa do problema e determinar a melhor forma de contorná-lo. Observou-se uma elevada geração de superfície específica granular somada à dificuldade de obter granulometria (-325\#) na moagem, além da elevação da umidade do filter cake. Além disso, observou-se uma considerável elevação do PPC (perda por calcinação) no período, o que explica as constatações anteriores. Os objetivos do trabalho são avaliar os efeitos do aumento do PPC no pellet feed na produção da pelota AFXX e buscar explicação para a queda da resistência à compressão.

Palavras-chave: PPC; Pelotização; Goethita.

\begin{abstract} Keywords: Goethite; Pelletizing; Spalling.

\footnotetext{
Engenheiro de processo, Vale, Brasil.

Técnico de processo, Vale, Brasil.

Engenheiro de operação, Vale, Brasil.

Gerente de Unidade Técnica, Vale, Brasil.
}

EFECT OF GOETHITE ON PELLETIZING PROCESS OF VALE

From the second half of 2013, a period of great difficulty answering the specification of compressive strength pellet AFXX was found. Thus, it was necessary to do from a complex diagnosis of all stages of the process to find the cause of the problem and determine the best way to get around it. There was a generation of granular high specific surface plus the difficulty of obtaining particle size $(-325 \#)$ in grinding, besides raising the moisture filter cake. In addition, there was a considerable rise of loss on ignition in the period, which explains the previous findings. The objectives are to evaluate the effects of the increase in loss on ignition in the production of pellet feed pellet AFXX and seek explanation for the decrease of the compressive strength.

\footnotetext{
* Contribuição técnica ao 44 Seminário de Redução de Minério de Ferro e Matérias-primas, 15ำ Simpósio Brasileiro de Minério de Ferro e 2ํㅗ Simpósio Brasileiro de Aglomeração de Minério de Ferro, 15 a 18 de setembro de 2014, Belo Horizonte, MG, Brasil.
} 


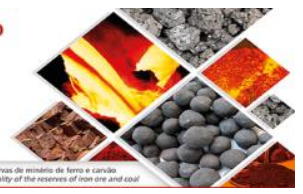

\section{INTRODUÇÃO}

Uma das plantas de pelotização da Vale produz a pelota AFXX destinada a alto forno cuja resistência à compressão é um parâmetro de extrema importância para o atendimento à qualidade exigida pelos clientes. Desta forma, a partir do maior dispêndio energético para controlar este requisito, iniciou-se um detalhado diagnóstico de processo envolvendo as operações unitárias. Após avaliar as análises químicas do pellet feed verificou-se o aumento do PPC, também conhecido como perda ao fogo, o que explicaria todos os sintomas observados em cada fase do processo. A figura 1 apresenta a evolução do PPC do pellet feed recebido ao longo do tempo com destaque para a acentuada elevação a partir de julho de 2013.

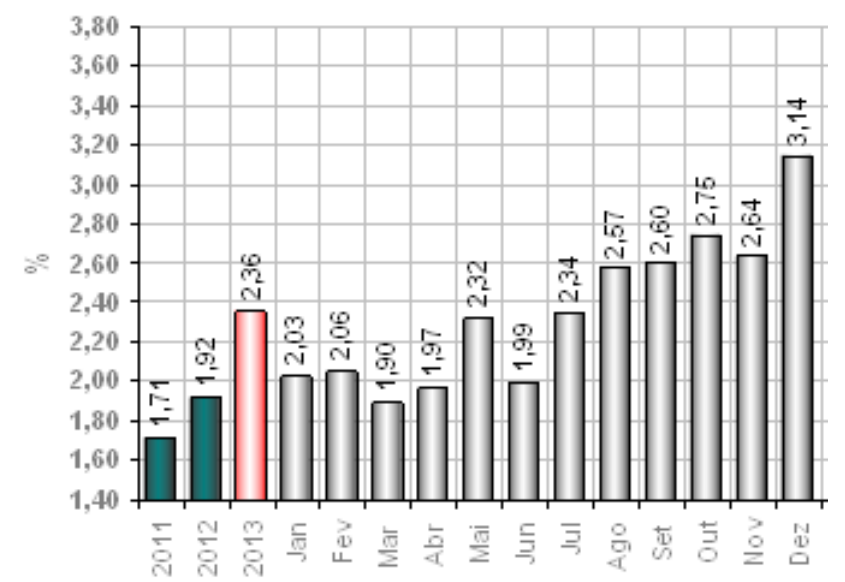

Figura 1 - Evolução do PPC do pellet feed recebido entre 2011 e 2013 na pelotização.

Sabe-se que o aumento do PPC está relacionado à presença de goethita no material e que a mesma possui características que desfavorecem as operações unitárias além de prejudicar as propriedades físicas da pelota queimada. A figura 2 mostra a relação entre o percentual de goethita e o teor de PPC.

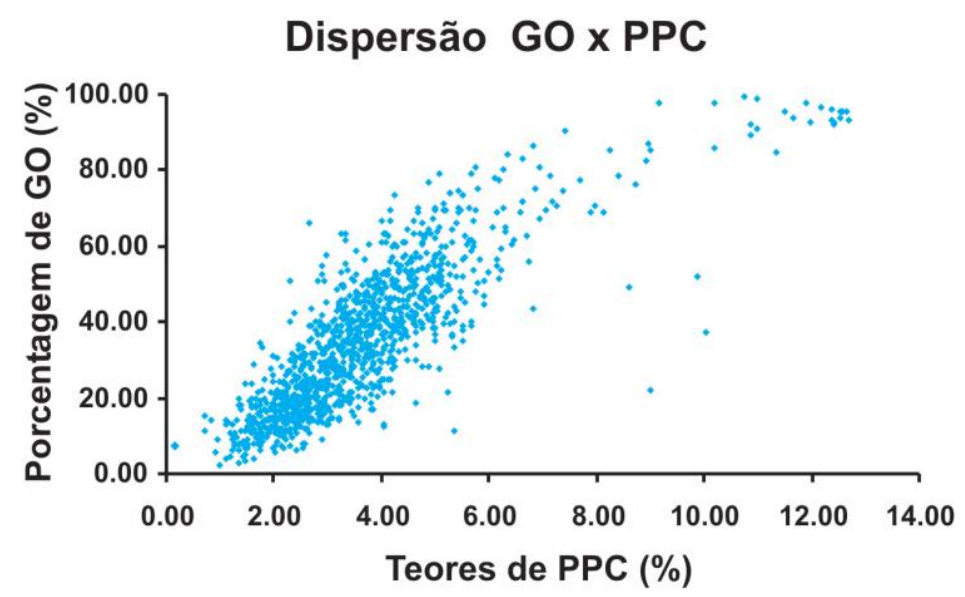

Figura 2 - Diagrama de dispersão goethita x PPC. [1]

As seguintes operações serão avaliadas: moagem, filtragem, prensagem, pelotamento e queima. Este trabalho discorrerá sobre os impactos deste material nas operações unitárias bem como na resistência à compressão da pelota queimada.

\footnotetext{
* Contribuição técnica ao 44 Seminário de Redução de Minério de Ferro e Matérias-primas, 15ำ Simpósio Brasileiro de Minério de Ferro e 2ํㅗ Simpósio Brasileiro de Aglomeração de Minério de Ferro, 15 a 18 de setembro de 2014, Belo Horizonte, MG, Brasil.
} 
Os objetivos do trabalho são avaliar os efeitos do aumento do PPC no pellet feed na produção da pelota AFXX e buscar explicação para a queda da resistência à compressão.

\section{MATERIAIS E MÉTODOS}

Este trabalho é baseado nos resultados obtidos no processo industrial da planta de pelotização no período de julho a dezembro de 2013. Desta forma, todas as análises químicas e físicas descritas foram realizadas no laboratório industrial seguindo as normas vigentes.

\subsection{Caracterização Mineralógica do Material}

Verifica-se que o minério apresenta cerca de $15 \%$ de goethita em sua composição tomando-se a média das três amostras analisadas (figura 3).

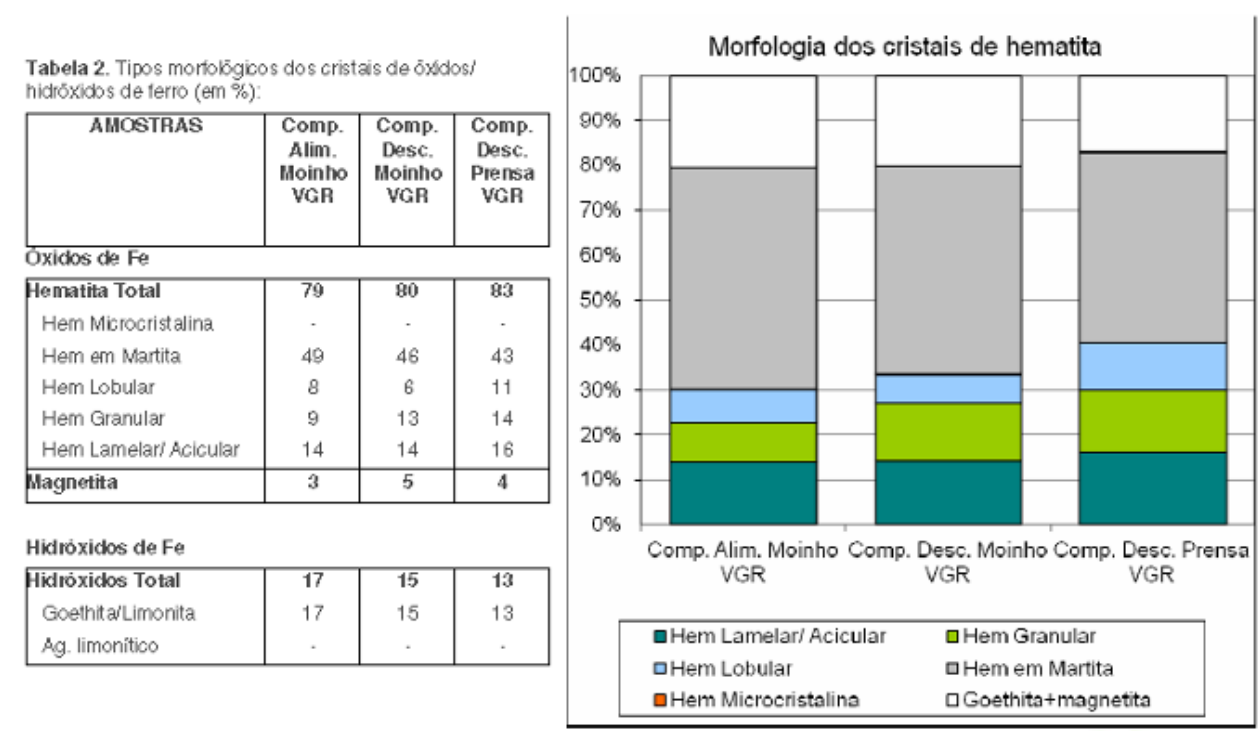

Figura 3. Caracterização mineralógica do pellet feed.

Observa-se que o PPC do pellet feed amostrado na descarga da prensa vem aumentando ao longo dos anos alcançando em 2013 valores pontuais acima de $3,0 \%$ (figura 4).

\footnotetext{
* Contribuição técnica ao 44 Seminário de Redução de Minério de Ferro e Matérias-primas, 15ำ Simpósio Brasileiro de Minério de Ferro e 2ํㅗ Simpósio Brasileiro de Aglomeração de Minério de Ferro, 15 a 18 de setembro de 2014, Belo Horizonte, MG, Brasil.
} 

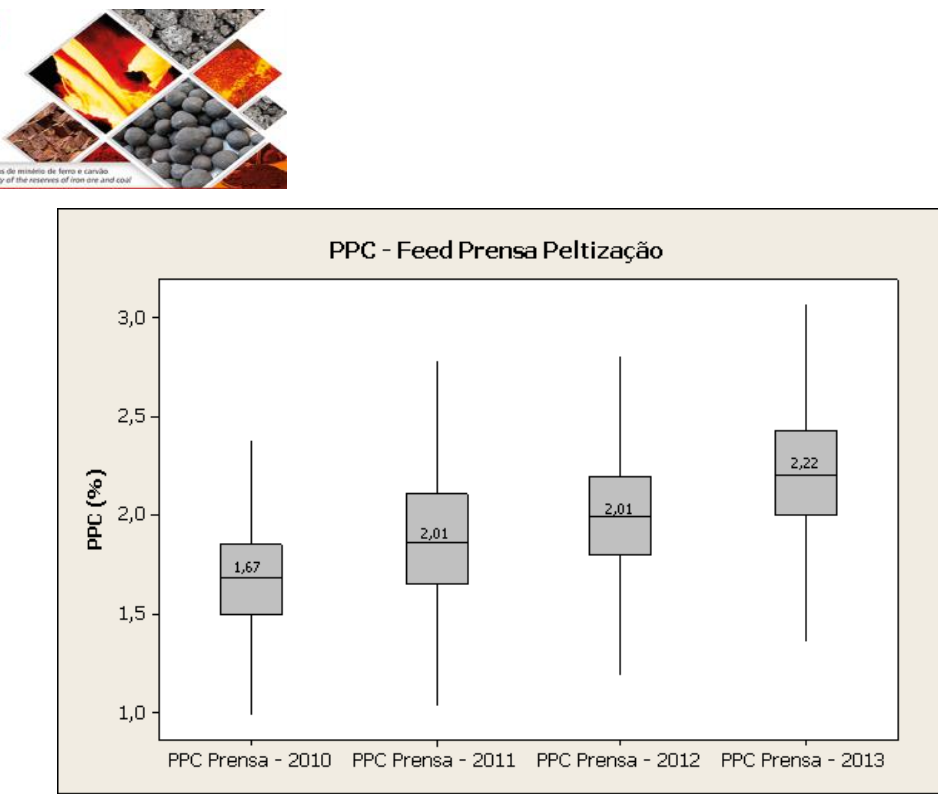

Figura 4. Média anual de PPC do pellet feed na descarga da prensa de rolos.

\section{APRESENTAÇÃO DOS RESULTADOS E DISCUSSÃO}

\subsection{Moagem}

Uma forte correlação é observada entre o percentual passante em $0,045 \mathrm{~mm}$, superfície específica e o PPC do pellet feed, conforme apresentado nas figuras 5 e 6 .

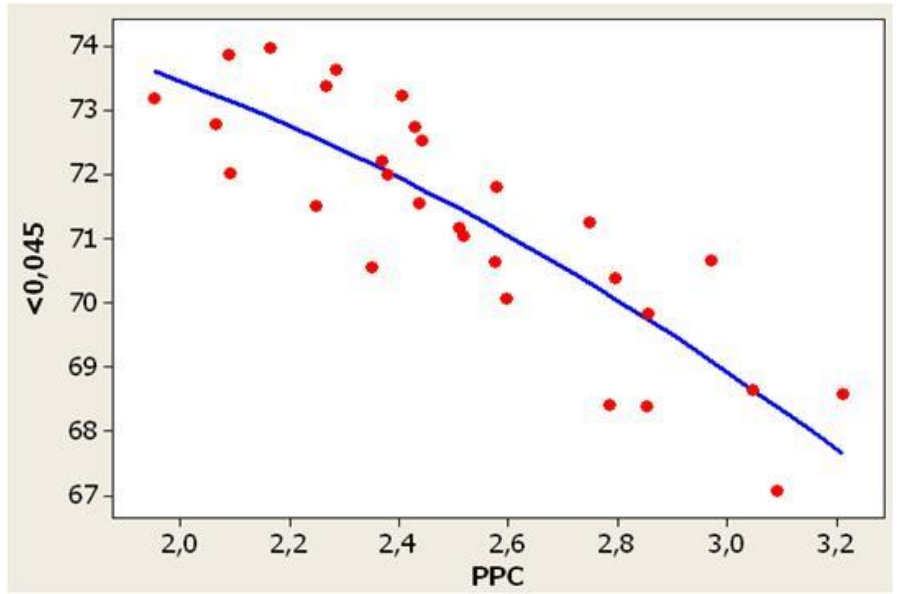

Figura 5. Percentual passante em $0,045 \mathrm{~mm}$ por faixa de PPC na descarga da moagem.

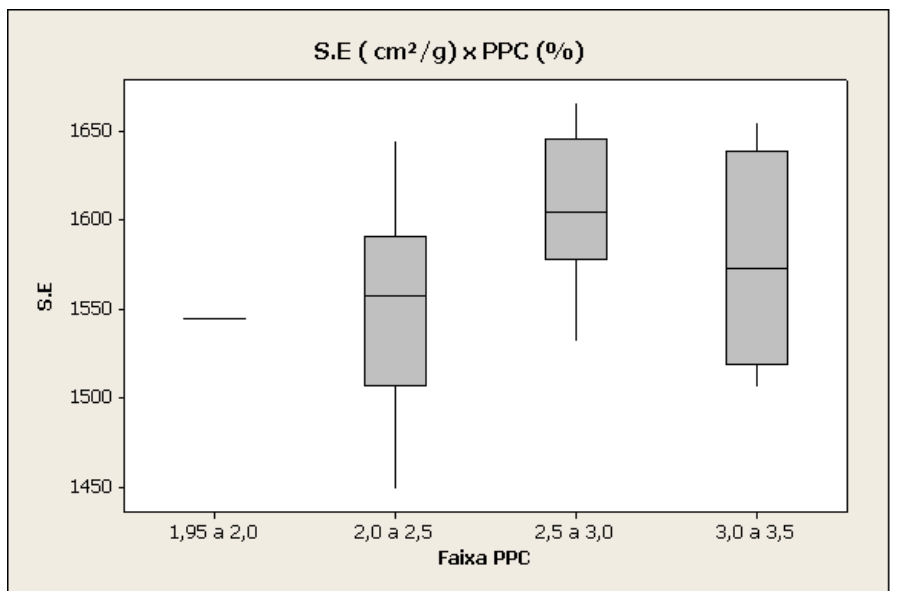

Figura 6 - Superfície específica por faixa de PPC na descarga da moagem.

* Contribuição técnica ao 44 Seminário de Redução de Minério de Ferro e Matérias-primas, 15은 Simpósio Brasileiro de Minério de Ferro e 2ํㅗํ Simpósio Brasileiro de Aglomeração de Minério de Ferro, 15 a 18 de setembro de 2014, Belo Horizonte, MG, Brasil. 
Foi verificado que o percentual passante em $0,045 \mathrm{~mm}$ reduz e a superfície específica aumenta com o aumento do PPC do pellet feed. A figura 7 apresenta a razão entre superfície específica e passante em $0,045 \mathrm{~mm}$ em função do PPC, onde está clara a maior geração de superfície específica em detrimento ao $<0,045 \mathrm{~mm}$, o que concorda com a literatura e com a experiência industrial recente de outras usinas de pelotização. Observa-se também a grande geração de lama, caracterizado pela fração passante em $0,01 \mathrm{~mm}$ (figura 8) Além das dificuldades apresentadas nas etapas de beneficiamento, a composição química do pellet feed apresenta menores teores de ferro e teores de $\mathrm{SiO}_{2}, \mathrm{P}$ e PPC mais elevados. Queda no peso específico e elevação significativa da porosidade e área superficial específica. Queda nos teores de hematita especular para valores abaixo de $20 \%$ e elevação da proporção de goethita em mais de duas vezes [2].

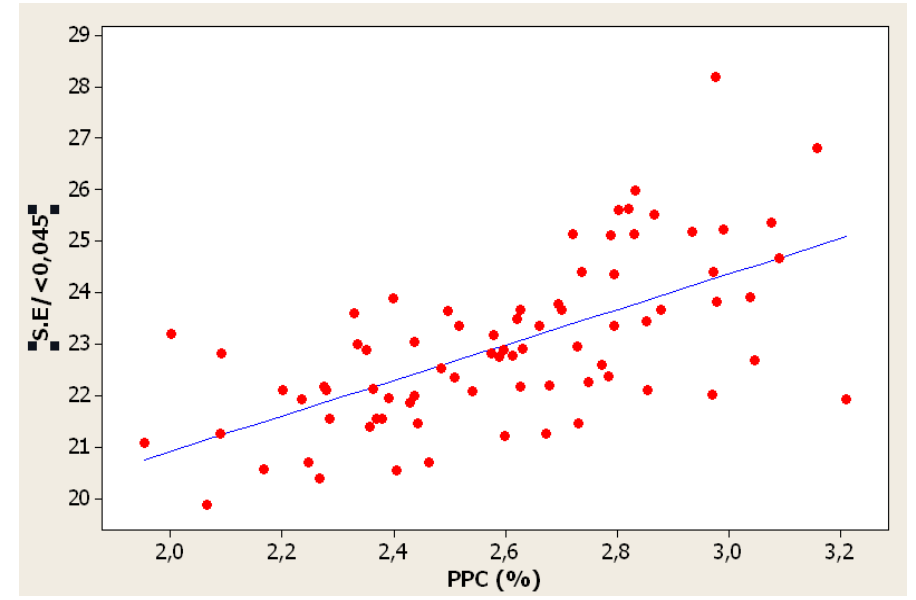

Figura 7 - Relação SE / <0,045 no pellet feed.

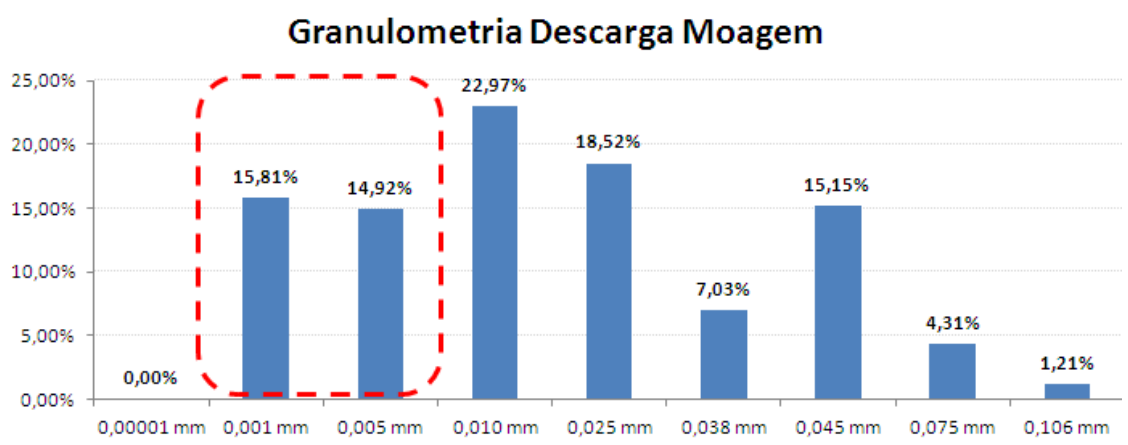

Figura 8 - Distribuição granulométrica na descarga da moagem.

Neste caso é necessário sacrificar o processo de moagem para garantir o mínimo de passante em $0,045 \mathrm{~mm}$ para minimizar as perdas nos processos subsequentes. A relação entre produção do moinho em função do $\%<0,045 \mathrm{~mm}$ mostra que é necessário reduzir $50 \mathrm{t} / \mathrm{h}$ de produção da moagem para ganhar $5 \%$ passante em $0,045 \mathrm{~mm}$ (figura 9).

* Contribuição técnica ao 44 Seminário de Redução de Minério de Ferro e Matérias-primas, 15ำ Simpósio Brasileiro de Minério de Ferro e 2ํㅗํ Simpósio Brasileiro de Aglomeração de Minério de Ferro, 15 a 18 de setembro de 2014, Belo Horizonte, MG, Brasil. 

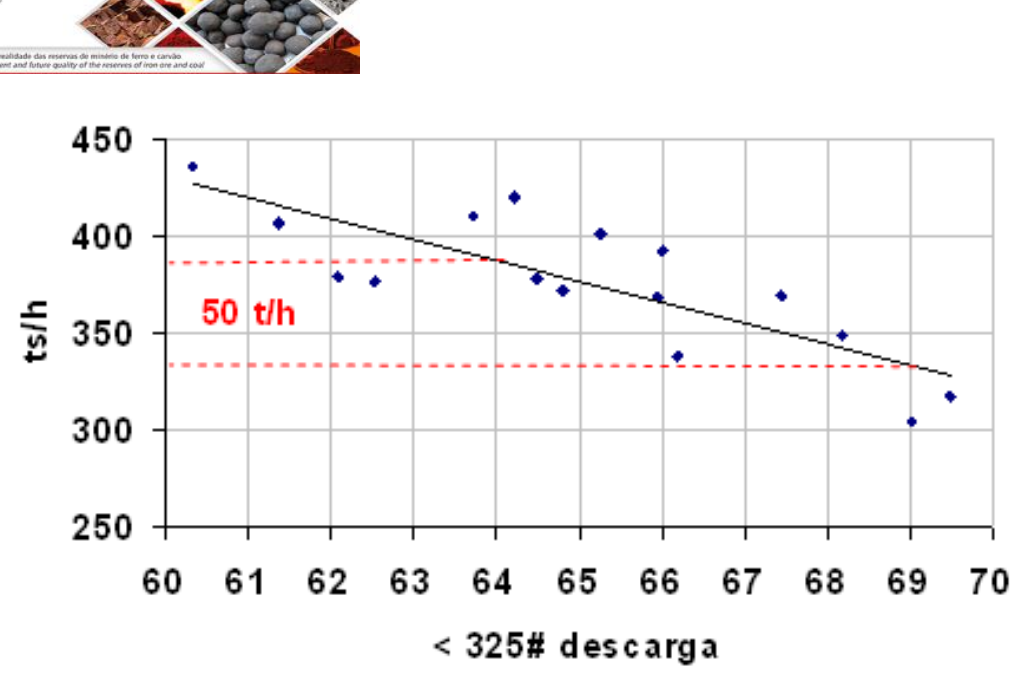

Figura 9 - Produção do moinho (tonelada seca) vs $\%<0,045 \mathrm{~mm}$.

\subsection{Filtragem}

Esta etapa do processo é fortemente influenciada pelo aumento do PPC. A relação entre a umidade da torta em função ao PPC do pellet feed (figura 10) mostra claramente que o aumento do PPC provoca a elevação do teor de umidade na torta.

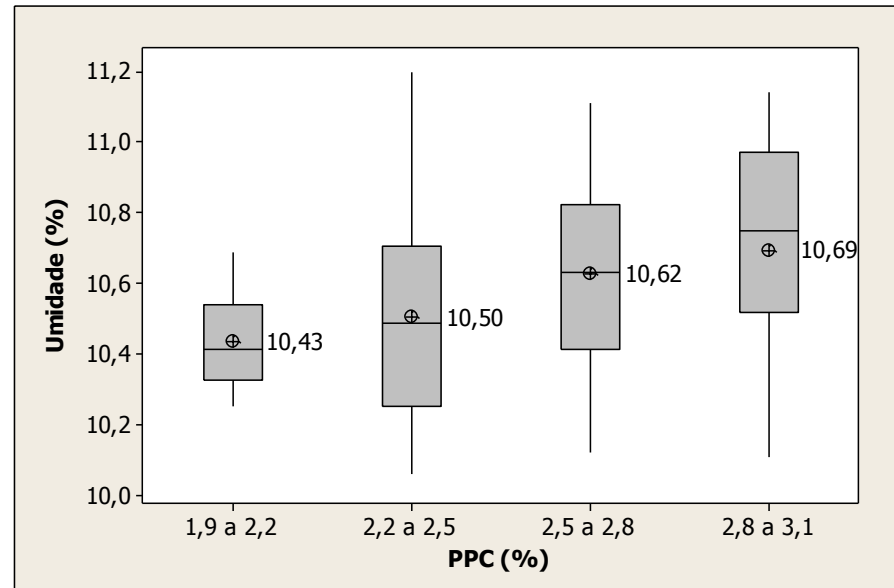

Figura 10 - Variação da umidade em função do aumento do PPC.

Sabe-se que aspectos como porosidade e forma das partículas afetam o desempenho da filtragem. Por isso, amostras com área superficial específica semelhantes, mas diferentes mineralogias, poderão apresentar comportamentos distintos na filtragem, principalmente se tiverem menor área superficial específica [7]. Os resultados industriais bem como a literatura também reportam a perda de produtividade na filtragem com o aumento do PPC $[2,7]$. Verifica-se a redução da produtividade média com o aumento do PPC do pellet feed variando entre $1,8 \%$ e $3,30 \%$ (figura 11).

* Contribuição técnica ao 44 Seminário de Redução de Minério de Ferro e Matérias-primas, 15ำ Simpósio Brasileiro de Minério de Ferro e 2ํㅗํ Simpósio Brasileiro de Aglomeração de Minério de Ferro, 15 a 18 de setembro de 2014, Belo Horizonte, MG, Brasil. 


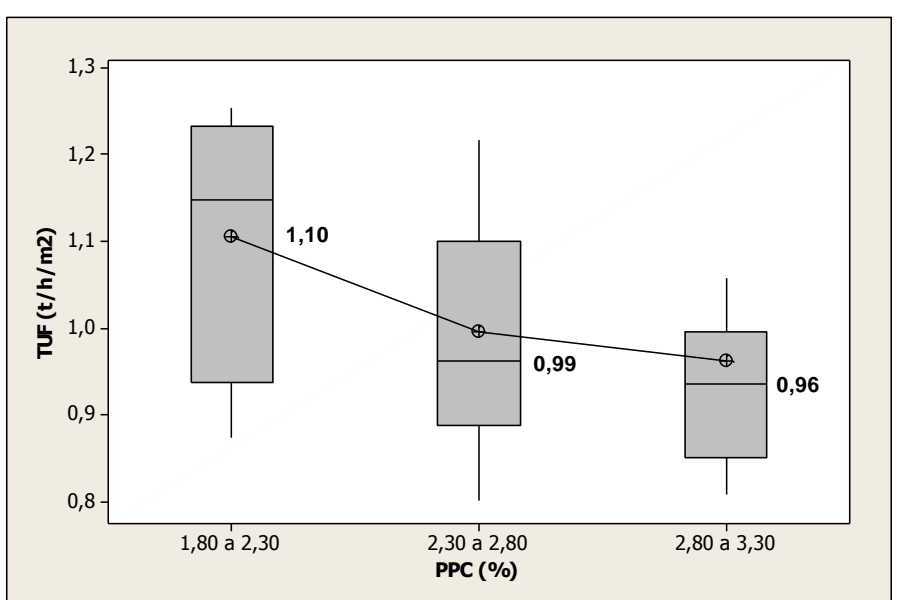

Figura 11 - Produtividade da filtragem em função do PPC do pellet feed.

\subsection{Prensa de Rolos}

Conforme apresentado anteriormente, minérios com elevado PPC, devido as suas características morfológicas, tendem a ter umidade elevada (figura 9) e, consequentemente, provocam menor torque na prensa, porém o suficiente para gerar um ganho de superfície específica mais elevada (figura 12). A literatura relata ganhos de granulometria $(<0,045 \mathrm{~mm})$ e elevação da superfície específica para materiais com PPC elevado, mesmo com aplicação de pressões mais baixas no processo [2].

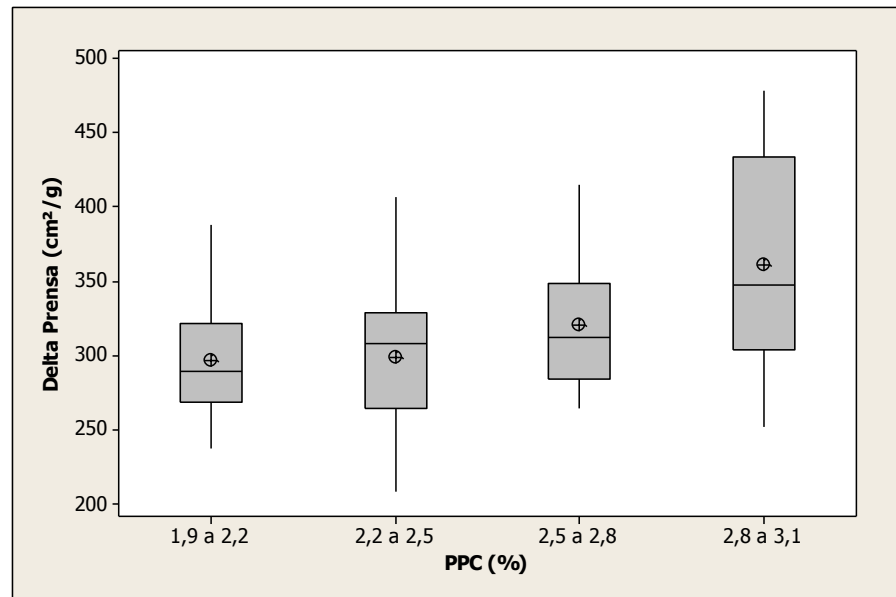

Figura 12 - Influência do PPC do pellet feed no ganho da prensa.

\subsection{Pelotamento}

O indicador retorno do pelotamento foi impactado positivamente com o aumento do PPC do pellet feed (figura 13). Verifica-se uma queda no retorno total independente do volume de produção avaliado.

* Contribuição técnica ao 44 Seminário de Redução de Minério de Ferro e Matérias-primas, 15은 Simpósio Brasileiro de Minério de Ferro e 2ํㅗํ Simpósio Brasileiro de Aglomeração de Minério de Ferro, 15 a 18 de setembro de 2014, Belo Horizonte, MG, Brasil. 


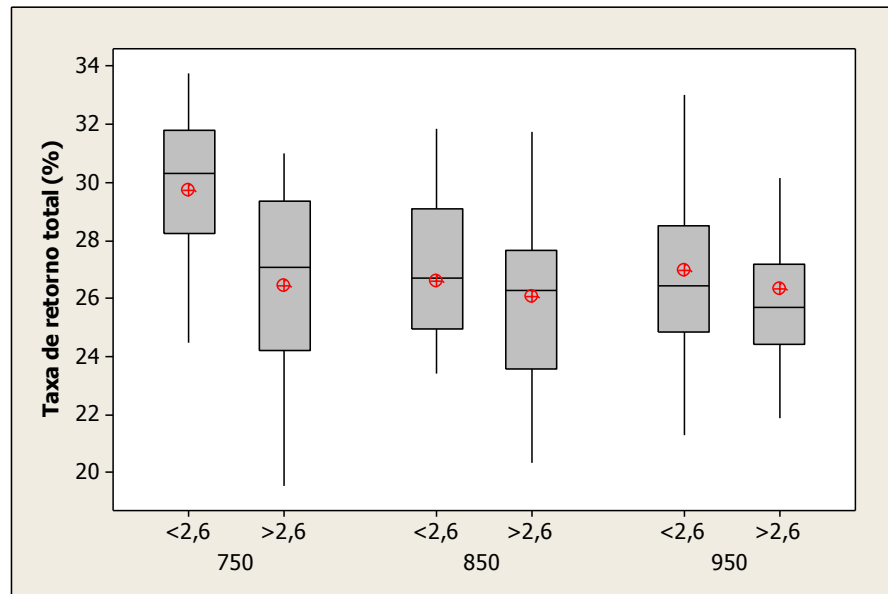

Figura 13 - Influência do PPC do pellet feed no retorno total.

Apesar dos resultados de compressão da pelota úmida (figura 14) apresentarem, em média, valores semelhantes, pode-se observar na distribuição dos dados certa tendência de aumento da resistência da pelota úmida com o aumento do PPC.

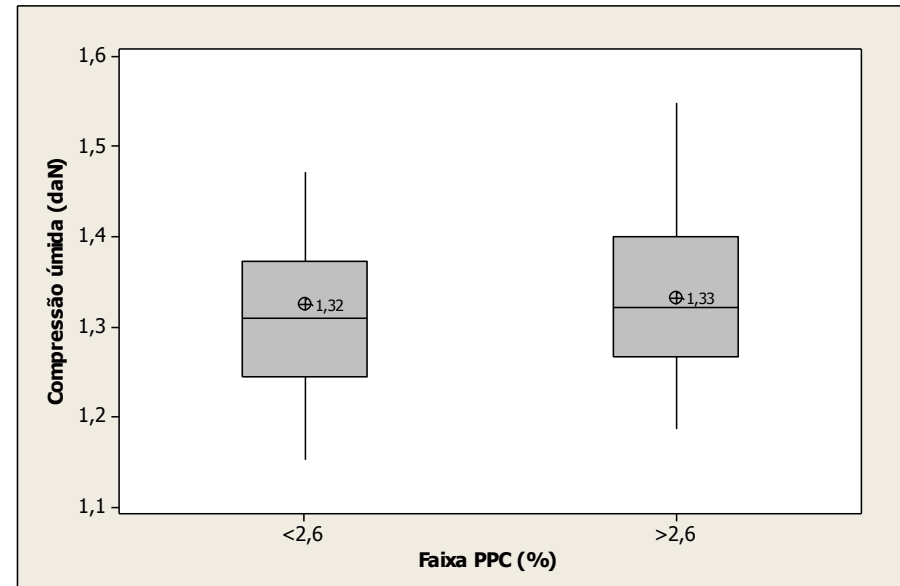

Figura 14 - Compressão da pelota úmida em função do PPC.

À medida que a fração de partículas finas aumenta, elas ocupam os espaços existentes entre as partículas maiores conferindo às pelotas uma maior compactação. Trabalhando-se com o grau de saturação ideal e com a umidade ideal no pelotamento, a tendência é que esta maior compactação se traduza em maior resistência física [8].

\subsection{Queima}

comportamento do processo de queima também é fortemente influenciado pelo aumento do PPC do pellet feed. Além dos impactos provocados pela transformação da goethita em hematita, o processo de queima também reflete as consequências dos processos anteriores, como a distribuição granulométrica e o aumento da umidade da pelota verde. No forno, o primeiro sintoma observado é o aumento (em módulo) das pressões das caixas de vento devido, principalmente, ao aumento da umidade da pelota verde. A figura 15 apresenta esta tendência.

* Contribuição técnica ao 44 Seminário de Redução de Minério de Ferro e Matérias-primas, 15º Simpósio Brasileiro de Minério de Ferro e 2ํㅗํ Simpósio Brasileiro de Aglomeração de Minério de Ferro, 15 a 18 de setembro de 2014, Belo Horizonte, MG, Brasil. 


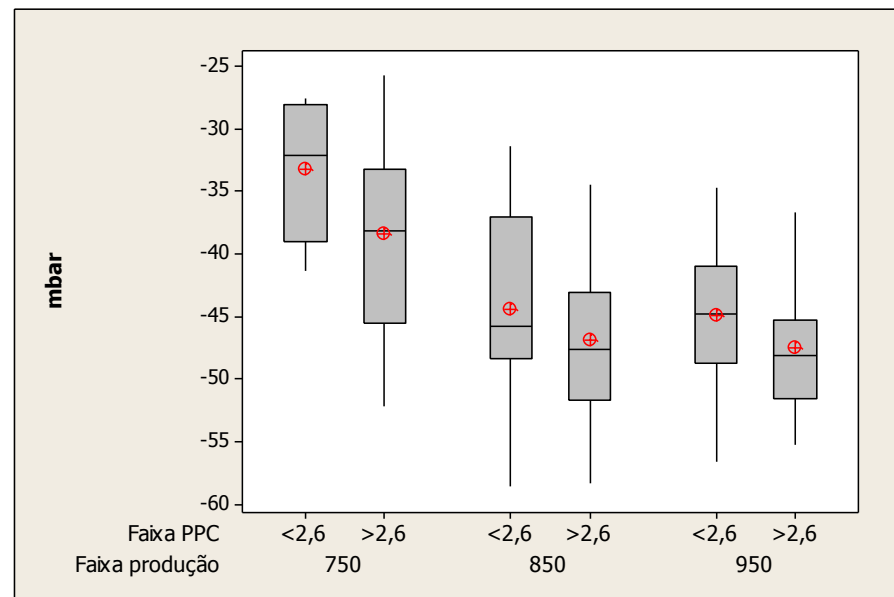

Figura 15 - Pressão na caixa de vento 5 , localizada na secagem descendente.

Observa-se que a pressão na caixa de vento da secagem descendente tende a ser mais negativa durante o processo do material com PPC superior a 2,6\%. Este comportamento é observado em todas as faixas de produção analisadas e, de certa forma, já era esperado devido o aumento de umidade que acompanha o aumento do PPC. Neste caso, para corrigir de imediato o problema no pelotamento, é comum o aumento da dosagem de bentonita na mistura o que aumenta a resistência da pelota verde. Além disso, o aumento da dosagem de bentonita aumenta a plasticidade da pelota o que reduz a permeabilidade do leito nas zonas de secagem e prejudica 0 mecanismo de oxidação da magnetita para hematita [3].

A estas pressões também se pode associar a possível ocorrência do fenômeno "spalling" que, com a degradação total ou parcial da pelota verde contribui para a redução da permeabilidade do leito na região da secagem descendente. Além disso, o fenômeno mencionado pode aumentar a geração de finos no produto final. A figura 16 apresenta os resultados do passante em 5,0 $\mathrm{mm}$ presente na pelota queimada após peneiramento. Este parâmetro é um dos itens de qualidade especificados no produto e deseja-se o menor valor possível.

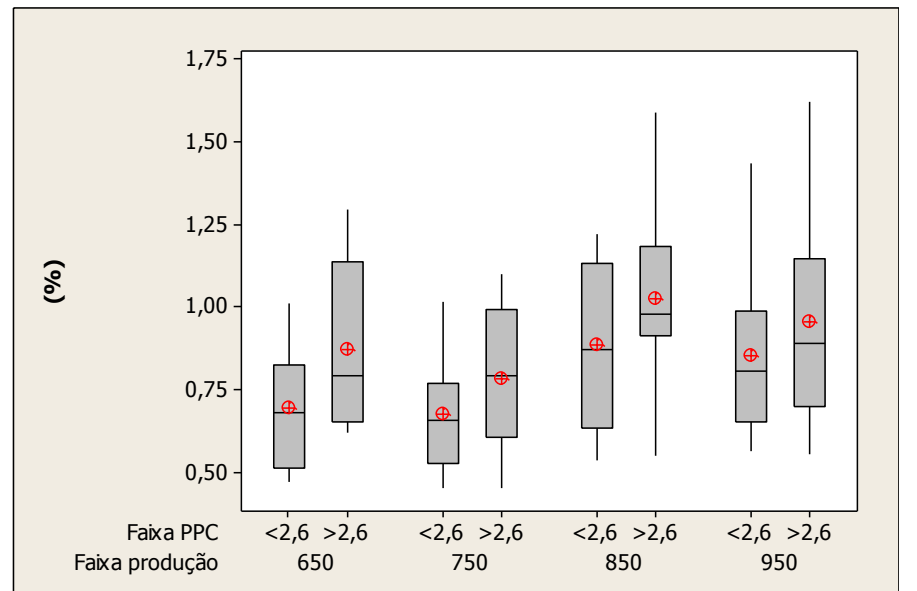

Figura 16 - Resultados do passante em 5,0mm em função da produção e PPC. A este parâmetro, deseja-se o menor valor possível.

O aumento do \%<5,0mm acompanha o aumento do PPC do pellet feed e pode estar relacionado com os fenômenos explicados anteriormente, além das dificuldades de processo apresentadas.

* Contribuição técnica ao 44 Seminário de Redução de Minério de Ferro e Matérias-primas, 15º Simpósio Brasileiro de Minério de Ferro e 2ํㅗํ Simpósio Brasileiro de Aglomeração de Minério de Ferro, 15 a 18 de setembro de 2014, Belo Horizonte, MG, Brasil. 
Foi observada a queda da resistência à compressão com o aumento do PPC (figura 17) para todas as faixas de produção avaliadas.

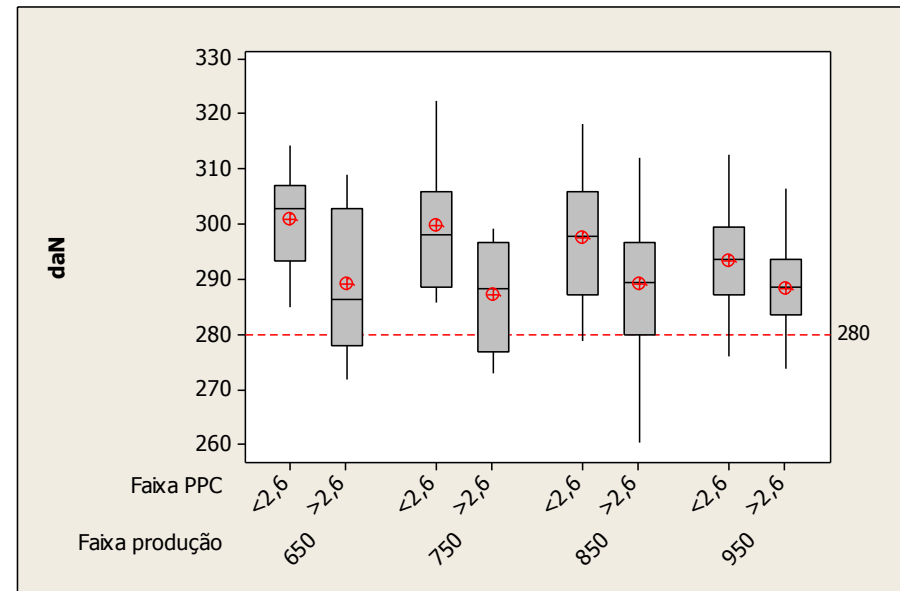

Figura 17 - Resultados de compressão média diária em função da produção e PPC.

A resistência à compressão é uma função da coesão da massa global das pelotas, visto que, quanto maior a área de contato entre as superfícies das partículas, maior será o fluxo atômico entre elas [8]. Sá et al. [4], através de regressão linear, encontraram a seguinte equação que correlaciona a compressão média com a mineralogia do pellet feed:

\section{Compressão média $(\mathrm{kg} /$ pelota $)=364.87-0.81^{*}$ Martita $-1.13^{\star}$ Goethita - 2.40*Magnetita ( 1 )}

A equação acima mostra a influência negativa da magnetita e da goethita na resistência à compressão da pelota. A goethita $(\mathrm{FeO}(\mathrm{OH}))$ decompõe-se a temperaturas próximas de $320^{\circ} \mathrm{C}$ em hematita e vapor. Esta temperatura pode variar em função da porosidade, resistência, taxa de transferência de calor e aditivos. Se a decomposição ocorrer de forma muito rápida, a liberação de calor pode causar o fenômeno "spalling" [5,6].

Observa-se um maior consumo específico de gás para o material com PPC acima de 2,6\% (figura 18), o que também está associado com a reação endotérmica de decomposição da goethita.

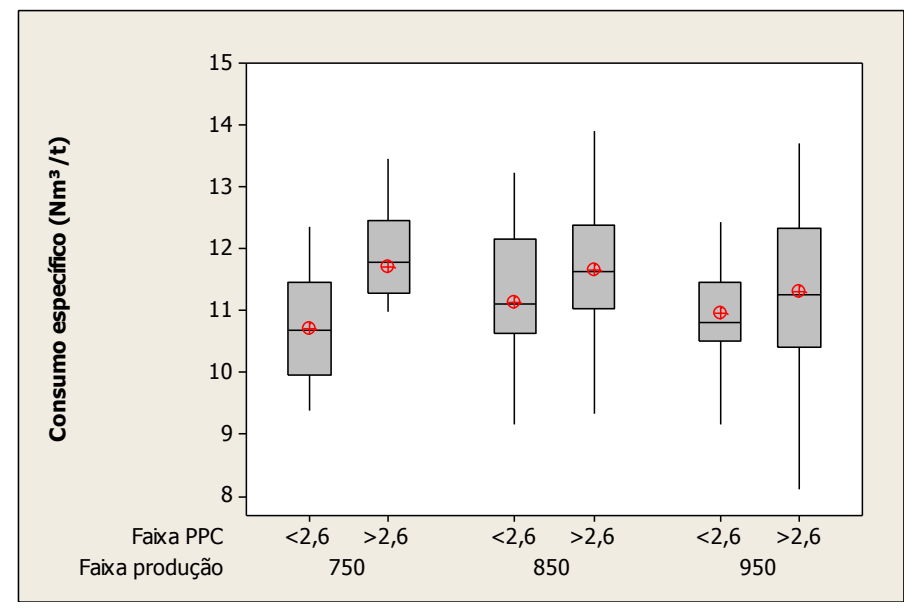

Figura 18 - Consumo específico de gás no processo de queima em função da produção e PPC.

\footnotetext{
* Contribuição técnica ao 44 Seminário de Redução de Minério de Ferro e Matérias-primas, 15ำ Simpósio Brasileiro de Minério de Ferro e 2ํㅗํ Simpósio Brasileiro de Aglomeração de Minério de Ferro, 15 a 18 de setembro de 2014, Belo Horizonte, MG, Brasil.
} 
aumento do PPC do pellet feed provoca a queda da temperatura alcançada pela pelota na região da queima, refletida na temperatura medida na última caixa de vento da queima (figura 19), o que está de acordo com a explicação anterior.

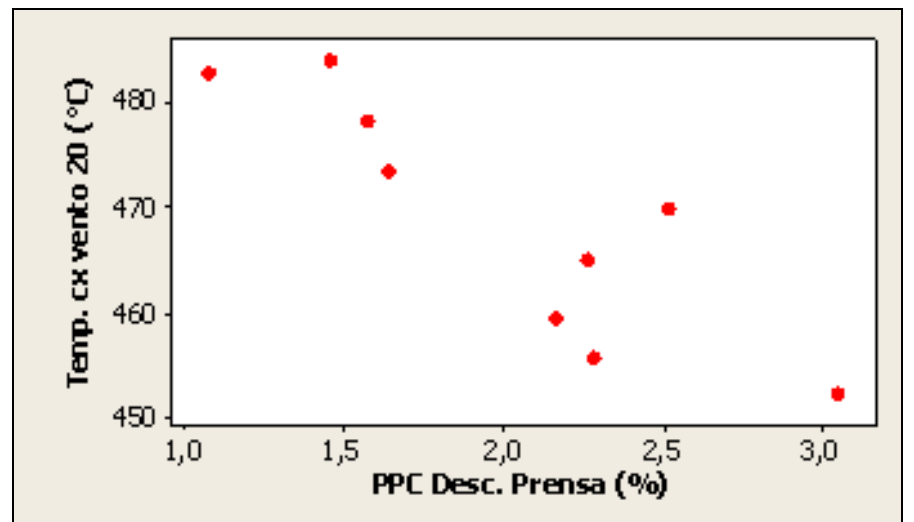

Figura 19 - Temperatura média da última caixa de vento da queima em função do PPC do material.

A influência da dosagem de carvão é mostrada na figura 20. A experiência indica que o comportamento varia de acordo com o PPC do pellet feed.

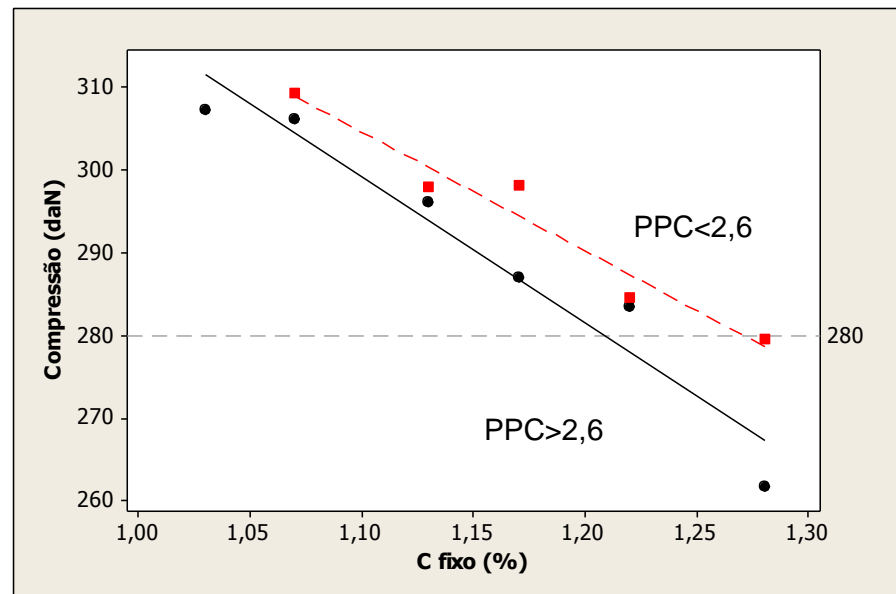

Figura 20 - Compressão média da pelota queimada em função do carbono fixo e do PPC.

O aumento do carbono fixo a partir de $1,0 \%$ tende a prejudicar a resistência à compressão da pelota queimada. Além disso, observa-se que, para pellet feed com PPC elevado, a pelota fica mais sensível ao aumento do carbono fixo. Para pellet feed com PPC abaixo de 2,6\% o processo tolera a adição de até, aproximadamente, $1,30 \%$ de carbono fixo mantendo a resistência à compressão acima de 280 daN/pelota. No caso do pellet feed com PPC maior que 2,6\%, essa tolerância cai para, no máximo, 1,20\%. Fonseca et al. [2] mostraram que o aumento do teor de carbono fixo afeta a qualidade física da pelota queimada devido ao aumento do número de poros após a queima do carvão, à formação de magnetita e ao crescimento das partículas de minério gerando elevadas tensões internas. Acreditase que, para o material com elevado PPC, o aumento do número de poros tenha a maior contribuição na queda de qualidade física da pelota pois a própria transformação da goethita já deixa grande quantidade de poros na pelota queimada. $\mathrm{O}$ controle das taxas de transferência de calor tanto na secagem (ascendente e descendente) quanto na pré-queima é de extrema importância para evitar a ocorrência do fenômeno denominado "spalling".

* Contribuição técnica ao 44 Seminário de Redução de Minério de Ferro e Matérias-primas, 15은 Simpósio Brasileiro de Minério de Ferro e 2ํㅗ Simpósio Brasileiro de Aglomeração de Minério de Ferro, 15 a 18 de setembro de 2014, Belo Horizonte, MG, Brasil. 
Algumas medidas estão sendo buscadas para minimizar os impactos da presença de goethita no pellet feed, tais como, adequação do \% carbono fixo em função do PPC, suavização do perfil de queima e redução da dispersão granulométrica para melhorar a permeabilidade do forno. O controle das taxas de transferência de calor tanto na secagem (ascendente e descendente) quanto na pré-queima é de extrema importância para evitar a ocorrência do fenômeno denominado "spalling".

\section{CONCLUSÕES}

O aumento do PPC do pellet feed provoca queda de produtividade, aumento de consumo térmico e redução da resistência à compressão da pelota AFXX.

\section{REFERÊNCIAS}

1 Remacre AZ, Botelho MC. O uso da Cokrigagem Co-Locada (collocated cokriging) na integração de dados químicos e mineralógicos no minério de ferro. REM: R. Esc. Minas. 2005; 58(1): 61-69.

2 Leonel CML. Estudo do processo de calcinação como operação unitária adicional na pelotização de minérios de ferro com altos valores de PPC [tese de doutorado]. Belo Horizonte: Universidade Federal de Minas Gerais; 2011.

3 Forsmo SPE, Samskog PO, Björkman BMT. A study on plasticity and compression strength in wet iron ore green pellets related to real process variations in raw material fineness. Powder Technology. 2008; 181: 321-330.

4 Sá KG, Costa GM, Vieira CB. Efeito da composição mineralógica na resistência à compressão de pelotas de minério de ferro.Tecnologia em Metalurgia, Materiais e Mineração. 2004; 1(2): 18-22.

5 Baker, LA, Armstrong, GJ, Cornelius, RJ, Lynch KS, Thomas CG. Effect of Goethite on Production Rate in a Traveling Grate Pellet Plant. In: Transactions of AIME. New York; 1973. p270-278.

6 Fonseca MC, Ferreira HO, Otaviano MM, Perim V. Influência da dosagem de carvão na qualidade das pelotas queimadas. In: Associação Brasileira de Metalurgia, Materiais e Mineração. Anais do $39^{\circ}$ Seminário de Redução de Minério de Ferro e Matérias-primas e $10^{\circ}$ Seminário Brasileiro de Minério de Ferro; 2009; Ouro Preto, Brazil. São Paulo: ABM; 2009.

7 Turrer HDG, Zuchi MA, Marchezi AS, Medeiros B, Simoes HO, Adail Mendes Araujo Junior AMA, et al. Efeito da Mineralogia na Filtragem de Minério de Ferro. In:

Associação Brasileira de Metalurgia, Materiais e Mineração. Anais do $41^{\circ}$ Seminário de Redução de Minério de Ferro e Matérias-primas e 12 Seminário Brasileiro de Minério de Ferro; 2011; Vila Velha; Brazil. São Paulo: ABM; 2011. p. 272-280.

8 Fonseca MC. Influência da distribuição granulométrica do pellet feed no processo de aglomeração e na qualidade da pelota de minério de ferro para redução direta [tese de doutorado].Ouro Preto: Universidade Federal de Ouro Preto; 2004.

* Contribuição técnica ao 44 Seminário de Redução de Minério de Ferro e Matérias-primas, 15ำ Simpósio Brasileiro de Minério de Ferro e 2ํㅗ Simpósio Brasileiro de Aglomeração de Minério de Ferro, 15 a 18 de setembro de 2014, Belo Horizonte, MG, Brasil. 